\title{
Outcome Of Surgical Treatment Of Tuberculosis Of The Spine In Patients With Motor Deficits
}

\author{
Bassam Mahmood Flamerz *
}

\section{ABSTRACT}

Background: Significant numbers of patients with spinal tuberculosis (TB), especially in developing countries, still present late after disease onset with severe neurological deficits.

Objective:This study was conducted to assess the outcome of surgery in patients with tuberculosis of the spine with motor deficits.

Type of the study: Retrospective study.

Methods: We retrospectively analyzed data obtained in all the patients with severe motor deficits due to spinal TB admitted to and surgically treated in four hospitals in Baghdad/Iraq during the period from January 2012 to January 2014. History, examination, imaging, histological, postoperative, and follow-up data were retrospectively culled from hospitals records and then analyzed. Data obtained in 48 patients with 6-24 months of follow up (mean follow-up period 12.8 months) were analyzed. The disease in 34 patients was characterized by Frankel Grade A/B and in 14 patients by Frankel Grade $\mathrm{C}$ at admission.

Results: Thirty (88\%) of the 34 patients with Frankel Grade A/B status and $13(92.8 \%)$ of the 14 patients with Frankel Grade $C$ status at admission experienced improvement to Frankel Grade D/E (walking with or without support) at the last follow-up examination after surgery. The degree of improvement exhibited by patients with a Frankel Grade A/B spinal cord injury was comparable to that shown by patients with Frankel Grade C status. Even patients with flaccid paraplegia, gross sensory deficit, prolonged weakness, spinal cord signal changes demonstrated on magnetic resonance imaging, and bladder involvement have experienced dramatic improvement in motor function since surgery. A significant number of the patients have shown remarkable improvement in other symptoms such as pain (91.6\%), spasticity (88\%), and bladder symptoms (88\%).

Conclusions: A significant proportion of patients with spinal TB and severe motor deficits experience remarkable improvement after surgical decompression and hence should undergo surgery even though they may be suffering from paraplegia of considerable duration.

KEY WORDS - tuberculosis • severe neurological deficits • Pott's disease $\cdot$ spinal instrumentation.

\section{Al-Kindy College Medical Journal 2017: Vol.13 No.1} Page: 56-62

\author{
*M.B.Ch.B F.I.C.M.S-Assistant Professor Of \\ neurosurgery/ Alkindy college of medicine-Consultant \\ Neurosurgeon
}

Received $15^{\text {th }}$ Feb 2017, accepted in final $30^{\text {th }}$ March 2017 Corresponding to : Bassam Mahmood Flamerz- Alkindy college of medicine
$\mathrm{E}$ vedince of spinal TB dates back to Egyptian times and has been documented in 5000-yearold mummies. In 1779, Percival Pott published the first modern description of spinal deformity and paraplegia resulting from spinal TB. ${ }^{(1)}$ Despite the availability of modern effective antituberculosis drugs and healthcare provisions, TB remains a serious health problem, especially in developing countries. According to a World Health Organization report in 2006, approximately one third of the world's population is infected by Mycobacterium TB, and 9 million individuals develop TB each year. ${ }^{(2)}$ Spinal TB occurs in fewer than $1 \%$ of patients with TB. ${ }^{(3,4,5)}$ The recent increase in the incidence of TB in developed countries may be related to the growing number of immunocompromised individuals and the increasing number of immigrants arriving from endemic areas. Vertebral TB is the most common form of skeletal TB and accounts for $50 \%$ of all cases of skeletal TB. ${ }^{(6,7,8)}$ Neurological complications are the most crippling complications of spinal TB with incidences ranging from 10 to $43 \%$ in various reports. $^{(9,10,11)}$ With advanced imaging techniques such as MR imaging, many cases of spinal TB are diagnosed earlier and patients are treated before they develop significant neurological deficits. Unfortunately we still see a significant number of patients presenting late after disease onset with severe neurological dysfunction. The frequent absence of concurrent pulmonary involvement and the healthcare personnel's lack of familiarity with the disease in developed countries mean that the diagnosis of TB poses a significant challenge. ${ }^{(12)}$

\section{Methods}

\section{Study Variables}

We retrospectively analyzed data obtained in all the patients with severe motor deficits due to spinal TB admitted to and surgically treated in four hospitals in Baghdad/Iraq during the period from January 2012 to January 2014. History, examination, imaging, histological, postoperative, and follow-up data were retrospectively culled from hospitals records and then analyzed. Cases in which the follow-up period was shorter than 6 months were excluded from this study. The Frankel classification system was used to grade the neurological dysfunction ${ }^{(13)}$ Grade A, no motor or sensory function below the level of injury; Grade B, some preserved sensation below the level of injury; 
Grade C, some preserved motor function below the level of injury but of no practical use to the patient; Grade D, preserved useful motor function below the level of injury (patient can walk with or without aid); and Grade E, normal motor and sensory function.

Frankel Grades A, B, and C were considered to reflect the presence of severe motor deficits. Frankel grades at last follow-up examination ( $\geq 6$ months postoperatively) were analyzed with appropriate tests to determine any statistically significant correlations. Continuous variables were analyzed using the independent samples t-test and the Mann-Whitney U-test, and categories were analyzed with the chi-square test. Statistical analysis was performed using SPSS 12.0 software for Windows (SPSS, Inc.). A probability value less than or equal to 0.05 was considered significant.

Patient Population: Overall 48 patients with severe deficits underwent surgery during the study period. These patients had been observed during a follow-up period of 6-24 months (mean 12.8 months). There were 27 male and 21 female patients who ranged in age from 7 to 75 years (mean age 33.3 years). The clinical presentation of these patients is summarized in Table 1. Fever was present in only 12 patients (25\%). Only one patient had concurrent pulmonary TB. The level of compression was cervical in eight patients, cervicothoracic in four, thoracic in 33 , thoracolumbar in two, and lumbar in one patient. All the patients suffered early-onset paraplegia. Twelve patients were already receiving antituberculosis treatment (ATT) at admission and presented with further progression of their initial minor deficits despite this therapy.

Table 1.Summary of presenting signs and symptoms in 48 patients with spinal TB

\begin{tabular}{|c|c|}
\hline Clinical Presentation & No. of Patients \\
\hline fever & 12 \\
pain & 36 \\
local & 34 \\
radicular & 5 \\
dysesthetic & 3 \\
motor deficits & 48 \\
Grade 0/5 power & 34 \\
Grade 1-3/5 power & 14 \\
spasticity & 42 \\
sensory deficits & 46 \\
bladder involvement & 34 \\
\hline
\end{tabular}

Frankel Grade at Admission. One patient was Frankel Grade A, 33 patients were Frankel Grade B, and 14 were Frankel Grade C.

Duration of Complete Paraplegia.: The duration of complete loss of bilateral lower-extremity movements in the 34 patients with Frankel Grade A or B injury was less than 1 month in 22 patients, 1-2 months in seven patients, 2-3 months in three patients, and 3-4 months in two pa-tients (range 1-120 days).
Vmaging Features: Magnetic resonance imaging predominantly revealed anterior compression with the involvement of the vertebral bodies in 38 patients and posterior compression with in-volvement of posterior elements in the remaining 10 patients. Kyphotic deformity was present in 25 patients. The number of vertebral levels of cord compression ranged from one to six. Signal changes in the cord (hyperintense signal on T2-weighted images) were observed in 10 patients.

\section{Operative Procedure}

Corpectomy and Fixation: Twenty-one patients underwent a corpectomy fixation procedure. In those with a cervical lesion an iliac crest graft was placed, titanium cage, and anterior cervical plate (Fig. 1). In those with thoracic and/or lumbar lesions a titanium cage was used, iliac crest graft and rod, and screw fixation (Fig. 2).

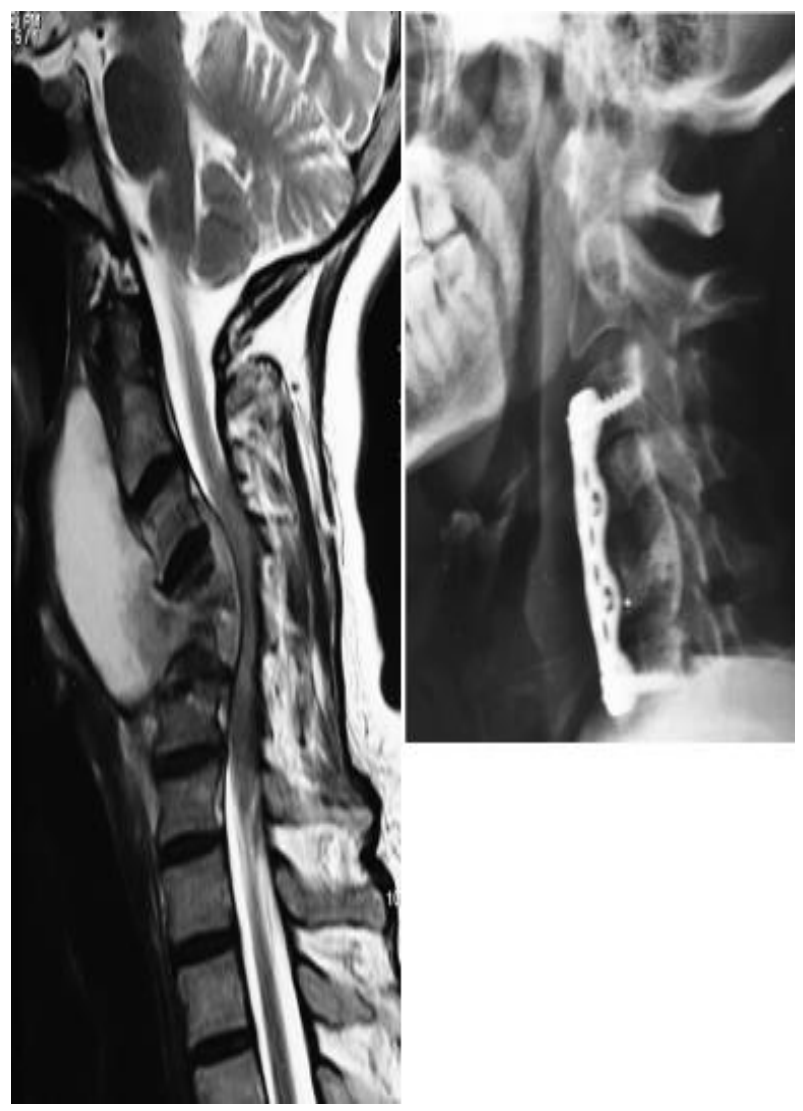

FIG. 1. Preoperative MR image (left) and postoperative radiograph (right) obtained in a patient presenting with spinal TB and severe deficits (Frankel Grade B).

Left: Note the C4-5 collapse, epidural and prevertebral collection, severe cord compression, and signal changes in the cord.

Right: Note the status of the spine after C4-5 corpectomy and fixation. The patient's muscle strength improved to Grade 5/5 after surgery. 


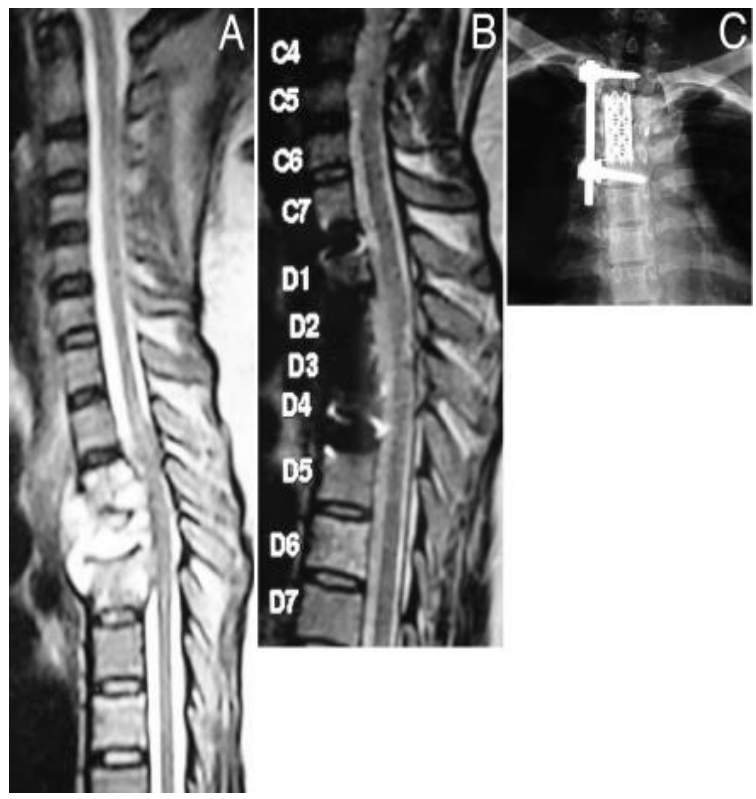

FIG. 2. Preoperative MR image (A), postoperative MR image (B), and postoperative radiograph

(C) obtained in a patient presenting with spinal TB and severe deficits (Frankel

Grade C).

A: Note the D2-3 collapse and cord compression.

B: Note the status of the spine after D2-4 corpectomy, titanium cage and rod fixation, and thecal sac decompression.

C: The spine-fitted titanium cage, screws, and rods.

The patient's lower-limb strength improved to Grade 5/5 after surgery.

Discectomy, Drainage, and Graft Placement: Two patients underwent cervical discectomy, drainage of fluid, and the placement of a graft for fusion.

Costotransversectomy and Drainage: Eleven patients underwent costotransversectomy followed by fluid drainage.

Laminectomy and Drainage: Fourteen patients underwent a laminectomy followed by fluid drainage.

The preferred operative procedure for anterior decompression was corpectomy and fixation, especially in the presence of severe kyphotic deformity, vertebral body col-lapse, anterior osseous compression, and mechanical instability. Radical drainage without fixation in cases involving anterior compression was performed only in the absence of the aforementioned factors and when the compression was predominantly caused by an abscess. Combined laminectomy and drainage was preferred when the compression was posterior. All patients were advised to undergo follow-up radiography at regular intervals to detect mechanical instability or progressive deformity and appropriate fixation.
Histopathological features were suggestive of TB in all of these patients.

Postoperative Management and Complications

Potent analgesics, aggressive chest and leg physiotherapy, respiratory exercises, and lower-limb elastic stockings were important parts of postoperative management. Chest tubes placed in patients after thoracotomy were removed once the drainage amount was less than $100 \mathrm{ml} /$ day and the chest $\mathrm{x}$-ray films demonstrated normal findings. Three patients developed pneumonia, and in one, a lung collapsed during the postoperative period; after aggressive chest physiotherapy and antibiotic therapy, all patients recovered. One patient developed deep vein thrombosis that completely resolved after treatment with heparin and oral anticoagulants. Because preoperative deficits in these patients were severe, ambulation-depending on the postoperative recovery-was started at the earliest point with all efforts at maintaining spinal stabilization (in cases of cervical TB, usually with a Philadelphia collar; in cases of thoracic or lumbar TB, with an appropriate spinal brace). This temporary spinal stabilization was advised for a minimum of 6 months and removed only when follow-up radiography revealed no evidence of spinal instability or deformity. The duration of hospital stay ranged from 10 to 17 days (mean 14.7 days). All patients took a full course of ATT for 12 to 18 months.

\section{Results}

\section{Clinical Outcome}

Pain: At the last follow-up examination, 33 of the 34 patients with local pain were symptom free and only one patient complained of mild local discomfort. Radicular pain improved completely in all five patients with this symptom. All of the three patients with dysesthetic pain were receiving medications (carbamazepine) and still complained of minimal pain.

Motor Deficits: (Frankel Grade at Discharge) At the time of discharge, only seven $(20.5 \%)$ of the 34 patients with Frankel Grade A/B status had improved to Frankel Grade D/E status. Function in 11 (78.5\%) of the 14 patients with Frankel Grade C improved to Frankel Grade $D / E$ by the time of discharge, but all of these patients continued to exhibit improvement, and the results of the final analysis were based on a patient's condition at the time of the last follow-up examination.

Motor Deficits: (Frankel Grade at the Last Follow Up) Function in $30(88 \%)$ of the 34 patients with Frankel Grade A/B at admission improved to Frankel Grade D/E, and the patients started walking with or without support, compared with the improvement seen in 13 (92.8\%) of 14 patients with admission Grade $C$ function at the time of the last follow up 6 months or more after surgery 
(Table 2). The degree of neurological recovery shown in patients with Frankel Grade A/B dysfunction was comparable with that shown in patients of Frankel Grade C dysfunction, and the difference was statistically insignificant $(p=0.494)$. Intramedullary tuberculoma was detected on MR imaging in one of the five patients in whom no postoperative improvement was shown immediately or even after more than 1 year of follow up. Table 2. Summary of Frankel grades at admission and last follow up*

\begin{tabular}{|c|c|c|}
\hline \multirow[t]{2}{*}{$\begin{array}{l}\text { Postoperative } \\
\text { FrankelbGrade }\end{array}$} & \multicolumn{2}{|c|}{$\begin{array}{l}\text { Admission Frankel Grade } \\
\text { (Number of patients) }\end{array}$} \\
\hline & $\mathrm{A}(1) \quad \mathrm{B}(33)$ & $C(14)$ \\
\hline$A$ & & \\
\hline$B$ & 4 & \\
\hline C & 1 & \\
\hline $\mathrm{D}$ & 17 & 9 \\
\hline$E$ & 12 & 4 \\
\hline
\end{tabular}

* Values represent the number of patients.

Spasticity: Forty-two (88\%) of the 48 patients suffered from bilateral lower extremity spasticity at admission. At the last follow-up examination, 37 (88\%) of these 42 patients exhibited remarkable improvement in spasticity; muscle tone was normal in 33 patients, mild spasticity persisted in four patients, and all 37 patients were walking with or without support. Significant spasticity persisted in five patients, of whom three were bed ridden and two were ambulating with support and receiving baclofen.

Sensory Deficits: Forty-two (91\%) of the 46 patients who presented with sensory deficits have experienced complete recovery. Only four noted persistent sensory deficits at the last follow-up visit.

Bladder Involvement: Thirty (88\%) of the 34 patients who presented with bladder involvement recovered complete function postoperatively. Only four patients noted persistent bladder involvement at the last followup visit. One patient experienced incontinence and an indwelling catheter had been placed. The remaining three patients complained of excessive straining during micturition.

Mechanical Instability: No radiographically documented mechanical instability was detected in any case through the last follow-up examination. There were no cases of implant failure among the 21 patients in whom corpectomy and fixation were performed. Follow-up data of 1 year or more were available in four of the 21 cases in which corpectomy and fixation were conducted. Radiography revealed signs of fusion in all of these patients. Due to short follow-up periods, it is difficult to determine the fusion rates.

Spinal Deformity: Kyphotic deformity was present in 25 patients at admission. Corpectomy and anterior fixation were performed in 21 of these patients. Intraoperative correction of the spinal alignment-either to a normal or acceptable level-under the guidance of flouroscopy was achieved in all of these patients. Alignment was maintained throughout the follow-up period in all of the patients and none required an additional posterior $\left(360^{\circ}\right)$ fixation. Radical drainage in cases without fixation was undertaken in three patients with minor kyphotic deformity; none had further progression of the deformity throughout the follow-up period.

In one patient with multiple cervical vertebral body involvement, kyphotic deformity, and associated atlantoaxial dislocation, C3-4 discectomy was performed, drainage of an anterior epidural abscess, and halo fixation. Because spinal deformity progressed despite the halo fixation, occiput-C7 lateral mass fusion was conducted. Normal alignment was maintained throughout the follow-up period. Another patient in whom any preoperative curvature was absent developed mild swan-neck deformity after cervical laminectomy and drainage; the patient was advised to undergo Philadelphia collar immobilization. Fixation was not undertaken in this case because the patient was asymptomatic, and there was no further progression of the deformity throughout the 2-year follow-up period.

\section{Analysis of Factors Affecting Recovery From Motor Deficits}

Age: A statistically significant correlation was observed between poor outcome and age greater than 50 years $(p$ $=0.015)$. Function in $33(97 \%)$ of the 34 patients younger than 50 years of age improved to Frankel Grade D/E compared with that in $10(71.4 \%)$ of the 14 patients older than age 50 years. The mean age of patients who did not improve after surgery was $52.2 \pm 22$ years ( \pm standard deviation) compared with $30.9 \pm 17$ years ( \pm standard deviation) in patients who improved after surgery.

Level of Compression: Function in 28 (84.8\%) of the 33 patients with dorsal compression improved to Frankel Grade D/E whereas that in the 15 patients with compression at other levels improved in all patients; however, the differences were not statistically significant $(p=0.405)$.

Flaccid Paraplegia: Function in 39 (92\%) of the 42 patients who presented with hypertonia improved to Frankel Grade D/E whereas this improvement was seen in four $(66 \%)$ of the six patients with flaccid paraplegia. Although a trend toward impaired neurological recovery was seen in patients with flaccid paraplegia, the difference was not statistically significant $(p=0.111)$.

Duration of Complete Bilateral Paraplegia in Patients With Frankel Grade A/B: Even patients with complete paraplegia of duration more than 2 months experienced remarkable improvement, with motor function in all five patients improving to Frankel Grade D/E.

Bladder Involvement: In extradural compression the bladder fibers become involved late after the lesion 
develops because they are more medial. Hence, bladder involvement that indicates the extent of cord compression was analyzed with final outcome. Status in $29(85 \%)$ of the 34 patients who presented with bladder involvement improved to Frankel Grade D/E at the last follow-up examination. Function in all 14 patients without bladder involvement at admission improved to Frankel Grade D/E. Although a trend toward impaired recovery was observed in patients presenting with bladder involvement, the correlations were statistically insignificant $(p=0.167)$.

Location of the Compression and the Operative Procedure: The surgical results after laminectomy/costotransversectomy and drainage were inferior compared with corpectomy/discectomy and drainage in patients with anterior compression, and the differences were statistically significant $(p=0.03)$ (Table $3)$.

Table 3. Correlation of the final Frankel grade with the location of compression and the operative procedure

\begin{tabular}{|c|c|c|}
\hline $\begin{array}{c}\text { Location of } \\
\text { (No. of } \\
\text { patients) }\end{array}$ & $\begin{array}{c}\text { Operation (No. of } \\
\text { patients) }\end{array}$ & $\begin{array}{c}\text { No. of } \\
\text { Patients } \\
\text { Improving to } \\
\text { Frankel } \\
\text { Grade D/E } \\
(\%)^{*}\end{array}$ \\
\hline anterior (38) & corpectomy \& fixation & $21(100)$ \\
& $(21)$ & $2(100)$ \\
posterior & discectomy \& & $10(91)$ \\
$(10)$ & drainage (2) & $2(50)$ \\
& costotransversectomy & \\
& \&drainage (11) & $8(80)$ \\
& laminectomy \& & \\
& drainage (4) & \\
& laminectomy \& & \\
& drainage (10) & \\
\hline
\end{tabular}

* Improvement to Frankel Grade D or E at the last followup examination.

Other Factors: Other factors analyzed including maximum sensory deficit, duration of weakness, duration of bladder involvement, number of vertebrae involved, and cord changes on MRI at admission did not show significant correlation with final outcome.

\section{Discussion}

Paraplegia is the most crippling neurological complication of spinal TB. In developing countries such as Iraq we still see a significant proportion of patients with spinal TB presenting late after onset of the disease with advanced paraplegia. ${ }^{(8,11)}$

\section{Outcome After Surgery}

Govender $^{(14)}$ analyzed 41 cases of spinal TB associated with severe neurological deficits (Frankel Grade A, six patients; Grade B, 18 patients; and Grade C, 17 patients) in which corpectomy and fixation were performed. The author reported complete neurological recovery at 12 months in $78 \%$. In his analysis of 44 patients with spinal TB and para- or quadriplegia, Tuli ${ }^{(11)}$ reported complete recovery in $63 \%$ after surgery.

Recovery rates ranging from 53 to $83 \%$ after surgery have been documented in several other

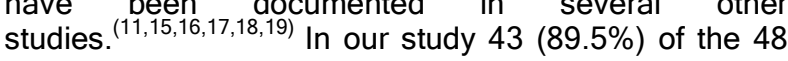
patients presenting with severe neurological deficits (Frankel Grade A, B, or C) experienced a functional improvement to Frankel GradeD or E. A direct comparison with other series is not possible because the criteria for defining paraplegia varied from series to series.

\section{Factors Affecting the Outcome}

Age: In our study, age greater than 50 years was found to be predictive of a poor outcome. A comparatively better outcome after surgery in younger patients was reported by others. ${ }^{(11,20,21,22)}$ In their study of experimental cord compression in dogs, Griffiths et al. ${ }^{(23,24)}$ noted that arteriolar dilation may compensate for and prevent spinal cord ischemia due to compression. In elderly patients arteriosclerosis may impair arteriolar dilation and, hence, increase the possibility of worsening of ischemia caused by spinal cord compression that results in impaired neurological recovery. ${ }^{(25,26)}$

Neurological Status at Admission: Tuli ${ }^{(11)}$ and $\mathrm{Ahn}^{(20)}$ found better outcomes in patients with incomplete paraplegia. Similar findings in patients with less severe deficits have been reported by others. ${ }^{(21,22)}$ In the present series, at the time of discharge only $20 \%$ of patients presenting with Frankel Grade $A / B$ dysfunction experienced an improvement to Frankel Grade D/E function in contrast to $78.5 \%$ of patients with Frankel Grade C. However, in $87 \%$ of patients with Frankel Grade A/B dysfunction compared with $92.8 \%$ of those with Frankel Grade C dysfunction, Frankel Grade D/E motor function was present at the last follow up. Although the rate of recovery was slower in patients with Frankel Grade A/B than in those with Frankel Grade C dysfunction, the final outcome in both the groups was comparable.

Level of Compression: Tuli ${ }^{(11)}$ noted partial or complete recovery after surgical decompression in $76 \%$ of his patients with spinal TB and para- or quadriplegia with thoracic compression compared with $83 \%$ at other levels. Moon and associates ${ }^{(19)}$ observed a higher incidence of paraplegia in patients with spinal TB in cases of thoracic involvement and noted a recovery in $86 \%$ of the latter patients compared with $91 \%$ in those with lesions at other levels. Chern et al. ${ }^{(25)}$ documented impaired recovery in patients with extramedullary tumors in the thoracic spine. The narrower spinal canal compared with the cord was the possible explanation given this finding. In the present series we also noted a trend toward impaired recovery in patients with thoracic compression: $84.8 \%$ improved to Frankel D/E compared 
with $100 \%$ in whom compression affected other spinal levels.

Duration of Paraplegia: Moula et al. ${ }^{(22)}$ found that the duration of paraplegia did not influence recovery after surgery whereas Moon et al. ${ }^{(21)}$ noted impaired recovery in patients with spinal TB and paraplegia of more than 6 months duration. In the present series, the recovery was not affected by the duration of paraplegia and patients with paraplegia of even 4 months duration have shown remarkable recovery.

Flaccid Paraplegia: Tuli et al. $^{(8)}$ reported impaired recovery in patients with flaccid paraplegia. A trend toward impaired recovery in patients with flaccid paraplegia was noted in the present series of patients.

\section{Posterior Surgery for Anterior Compression}

Garst $^{(27)}$ considered that only laminectomy is contraindicated except when posterior elements are involved. Rand and Smith ${ }^{(28)}$ reported finding neurological deterioration due to progressive kyphosis in five of the 16 patients with anterior spinal TB after laminectomy. Laminectomy results in the removal of a normal healthy vertebral segment in an already unstable spine. Laminectomy to treat anterior spinal disease was undertaken in four patients during the initial part of our study and is no longer performed.

\section{Mechanical Instability and Deformity}

Only radical drainage without fixation can result in mechanical instability or progressive deformity and may require fixation. ${ }^{(12,28)}$ One patient in our study developed spinal instability after radical drainage was performed without fixation. Two patients developed deformity after radical drainage without fixation.

\section{Conclusions}

A significant proportion of the patients with spinal TB and severe deficits exhibit remarkable improvement in sensory, motor deficits, spasticity, bladder symptoms, and pain and can lead an independent life after surgical decompression combined with ATT. No patient with spinal TB and severe deficits-including the patients with flaccid paraplegia, advanced bladder involvement, Grade 0/5 lower-limb strength, gross or complete sensory deficits, and prlonged paraplegia-should be considered too ill to undergo surgical decompression, and hence surgery must be encouraged in all of these cases. Impaired recovery is seen in patients older than 50 years of age, in patients with dorsal compression, and in patients in whom posterior decompression is undertaken for anterior disease. The improvement shown by patients with Frankel Grade A/B (Grade 0/5 lower-limb strength at admission) after surgical decompression is comparable with that shown in patients with Frankel Grade C. Only radical drainage without spinal fixation can lead to unstable spine/deformity, and thus patients after this procedure must be carefully evaluated and appropriate fixation undertaken once instability or significant progressive deformity is detected.

\section{References}

1-Seddon HJ: Pott's paraplegia, Prognosis and treatment. Br J Surg1935; 22:769-799,

2-Bjune $G$ et al: Guidance for national tuberculosis programs on the management of tuberculosis in children. World Health Organization:8-9, 2006 (http: //www.stoptb.org/wg/dots_expansion/assets/documents/ TBChildGuide.pdf) [Accessed 2 February 2007]

3-Fam AG, Rubenstein J: Another look at spinal tuberculosis. J Rheumatol,1993; 20:1731-1740,

4-Halsey JP, Reeback JS, Barnes CG: A decade of skeletal tuberculosis. Ann Rheum Dis 1982; 41:7-10,

5-Janssens JP, de Haller R: Spinal tuberculosis in a developed country. A review of 26 cases with special emphasis on abscesses and neurologic complications. Clin Orthop Relat Res .1990;257:67-75,

6-Konstam PG, Blesovsky A: The ambulant treatment of spinal tuberculosis. Br J Surg , 1962;50:26-38,

7-Kumar R: Spinal tuberculosis: with reference to the children of northern India. Childs Nerv Syst.2005; 21:1926,

8-Tuli SM, Srivastava TP, Varma BP, Sinha GP: Tuberculosis of spine. Acta Orthop Scand .1967;38:445458,

9-Bailey HL, Gabriel M, Hodgson AR, Shin JS: Tuberculosis of the spine in children. Operative findings and results in one hundred consecutive patients treated by removal of the lesion and anterior grafting. $J$ Bone Joint Surg Am1972; 54:1633-1657,

10-Risko T, Novasazel T: Experience with radical operations in the tuberculosis of the spine. J Bone Joint Surg Am .1963;45:53-68,

11-Tuli SM: Treatment of neurological complications in tuberculosis of the spine. J Bone Joint Surg Am .1969;51:680-692,

12-Nussbaum ES, Rockswold GL, Bergman TA, Erickson DL, Seljeskog EL: Spinal tuberculosis: a diagnostic and management challenge. J Neurosurg .1995;83:243-247,

13-Frankel HL, et al: The value of postural reduction in the initial management of closed injuries of the spine with paraplegia and tetraplegia. I. Paraplegia. 1969; 7:179-192,

14-Govender S: The outcome of allografts and anterior instrumentation in spinal tuberculosis. Clin Orthop Relat Res .2002;398: 60-66,

15-Acikgoz B, Ozcan OE, Belen D, Erbengi A, Ozgen T: Surgery for progressive Pott's paraplegia (tuberculous paraplegia). Paraplegia ,1991;29:537-541,

16-Guirguis AR: Pott's paraplegia. J Bone Joint Surg Br 49:.1967; 658-667,

17-Hodgson AR, Stock FE: Anterior spinal fusion. A preliminary communication on the radical treatment of Pott's disease and Pott's paraplegia. 1956. Clin Orthop Relat Res.1994; 300:16-23,

18-Lifeso RM, Weaver P, Harder EH: Tuberculous spondylitis in adults. J Bone Joint Surg Am .1985;67:1405-1413,

19-Moon MS, Ha KY, Sun DH, Moon JL, Moon YW, Chung JH: Pott's paraplegia-67 cases. Clin Orthop Relat Res.1996; 323: 122-128,

20-Ahn BH: Treatment for Pott's paraplegia. Acta Orthop Scand. 1968;39:145-160, 
21-Moon MS, Moon JL, Moon YW, Kim SS, Kim SS, Sun $\mathrm{DH}$, et al: Pott's paraplegia in patients with severely deformed dorsal or dorsolumbar spines: treatment and prognosis. Spinal Cord 2003;41:164-171,

22-Moula T, Fowles JV, Kassab MT, Sliman N: Pott's paraplegia: a clinical review of operative and 23-Griffiths IR: Vasogenic edema following acute and chronic spinal cord compression in the dog. J Neurosurg 1975;42:155-165

24-Griffiths IR, Trench JG, Crawford RA: Spinal cord blood flow and conduction during experimental cord compression in normotensive and hypotensive dogs. J Neurosurg 1979; 50:353-360,

25-Chern SH, et al: Prognostic factors of intra spinal neurilemmoma and menin-gioma with severe preoperative motor deficits. J Formos Med Assoc 1993;92:227-230,

26-Ciappetta P, Domenicucci M, Raco A: Spinal meningiomas: prognosis and recovery factors in 22 cases with severe motor deficits. Acta Neurol Scand 1988;77:27-30,

27-Garst RJ: Tuberculosis of the spine: a review of 236 operated cases in an underdeveloped region from 1954 to 1964. J Spinal Disord 1992; 5:286-300,

28-Rand C, Smith MA: Anterior spinal tuberculosis: paraplegia following laminectomy. Ann R Coll Surg Engl 1989;71:105-10 